\title{
Uma Investigação acerca das Percepções dos Discentes do Brasil e de Portugal sobre a Convergência da Contabilidade aos Padrões Internacionais
}

\author{
An Investigation on Students' Perceptions of Brazil and Portugal on the Convergence of \\ International Accounting Standards
}

\author{
Leonardo da Costa \\ leonardomdacosta@gmail.com \\ UFPE \\ Umbelina Lagioia \\ umbelinalagioia@gmail.com \\ UFPE
}

\author{
Suênia Nascimento \\ oliveirasuenia@hotmail.com \\ UFPE \\ Juliana de Araújo \\ juhliana.araujo@gmail.com \\ UFPE
}

\author{
Lívia Lemos \\ livia27.07@gmail.com \\ UFPE
}

\begin{abstract}
Resumo: Esta pesquisa teve como principal objetivo verificar as percepções dos discentes de universidades no Brasil e em Portugal perante o processo de convergência da contabilidade aos padrões internacionais. Para tanto, a pesquisa se deu na forma de aplicação de questionários estruturados aos discentes de Instituições de Ensino Superior do Brasil e de Portugal. O estudo é baseado em uma amostra de 159 respondentes, sendo 112 estudantes brasileiros e 47 estudantes de Portugal. Os dados foram tratados por meio da analise descritiva dos dados, com auxílio do software Statistical Package for the Social Sciences SPSS®, renomeado para Predictive Analytics Software (PASW). O estudo concluiu que 92\% dos brasileiros e $72,4 \%$ dos portugueses afirmaram concordar que o processo de convergência das normas brasileiras de contabilidade às normas internacionais é bem vindo, pois traz mais benefícios do que custos às empresas. Os resultados revelaram também que $84,9 \%$ dos discentes do Brasil e 57,4\% dos discentes de Portugal afirmaram que não acreditam na capacitação dos profissionais de contabilidade para as mudanças decorrentes da adoção das normas do IASB, demonstrando que os mesmos percebem que os contabilistas estão despreparados para colocar em prática as mudanças.
\end{abstract}

Palavras-Chave: Normas Internacionais; Discentes; Brasil; Portugal.

Abstract: This research aimed to examine the perceptions of students from universities in Brazil and Portugal before the process of convergence to international standards of accounting. Therefore, the research took the form of structured questionnaires to students of higher education institutions in Brazil and Portugal. The study is based on a sample of 159 respondents, of which 112 Brazilian students and 47 students from Portugal. The data were treated by descriptive analysis of the data, using the software Statistical Package for Social Sciences - SPSS ${ }^{\circledR}$, renamed Predictive Analytics Software (PASW). The study concluded that 92\% of Brazilians and $72.4 \%$ of the Portuguese claimed agree that the convergence of Brazilian accounting standards with international standards is welcome because it brings more benefits than costs to businesses. The results also revealed that $84.9 \%$ of students in 
Brazil and 57.4\% of students in Portugal said they do not believe in professional training for accounting changes resulting from the adoption of IASB standards, demonstrating that they realize that accountants are unprepared to enact the changes.

Keywords: International Standards; students; Brazil, Portugal.

Artigo recebido em: 01.11.2012; Aceito em: 30.01 .2013

\section{INTRODUÇÃO}

A sucessão de fatos e acontecimentos socioeconômicos ocorridos no final do século $\mathrm{XX}$ alterou a forma de organizar e relacionar as empresas em termos globais. $\mathrm{O}$ atual ambiente econômico, onde é possível observar o fim das barreiras comerciais entre países e do desenvolvimento do mercado de capitais, demanda uma maior ênfase em conceitos como a universalidade, a comparabilidade aos negócios e as regras de preparação e apresentação de contas das empresas.

Como afirma Iudícibus (2002, p. 44), o grau de avanço da Contabilidade está diretamente associado ao grau de progresso econômico e institucional de cada sociedade. Este grau de progresso é distinto em cada país, e outras questões como o sistema jurídico-legal, fatores históricos e sociais surgem como diversidades contabílisticas e tornam-se entraves para o alcance de uma comparabilidade contábil a nível internacional.

Contudo, a contabilidade como ciência social, deve adaptar-se às tais mudanças ambientais que surgem e, portanto, auxiliar a tomada de decisão de seus usuários com informações confiáveis e relevantes (IJIRI 1975). Desse modo, a harmonização, classificada por Evans, Taylor, Holzmann, 1994 (apud WEFFORT, 2005) e Radebaugh e Gray (1997) como o processo de aproximação das normas e práticas contábeis entre os países, através do estudo das causas relativas as diferenças internacionais, apresenta-se como alternativa para minimizar a diversidade contabilística.

Na opinião de autores como Lourenço e Morais (2004:40) e Neto et al. (2004:284), a harmonização contabilística consiste em um processo mais flexível e aberto ao comparar-se com a normalização, pois atende às especificidades econômicas, sociais e culturais de cada país, sendo por isso de fácil implementação. É na vertente da harmonização que o IASB (International Accounting Standars Board), órgão independente com o objetivo de elaborar e publicar normas contábeis a serem seguidas nos relatórios financeiros, foi criado.

As normas internacionais de relatórios financeiros, IFRS, elaboradas pelo IASB, assentam em princípios que estabelecem limites de variações ao invés de regras rígidas, corroborando a sua adesão a nível mundial. Além desse fato, as IFRS são emitidas após uma sucessão de atividades, incluindo-se audiências públicas, sendo assim, de acordo com Lemes e Carvalho (2010), impossível a prevalência de posicionamentos destituídos de fundamento teórico, conceitual ou de respeito à realidade econômica.

No Brasil, a convergência às normas internacionais adveio principalmente dos esforços realizados pelo Comitê de Pronunciamentos Contábeis na elaboração de normas harmonizadas com os padrões do IASB. Além disso, a partir de 2010, o Banco Central do Brasil (Bracen) e a Comissão de Valores Mobiliários (CVM) tornaram obrigatória a adoção integral das normas IFRS para as entidades reguladas e supervisionadas por tais autarquias. Desta forma, o Brasil posiciona-se como um dos únicos países do mundo a implementar, por força legal, as normas internacionais nos balanços individuais das empresas (LEMES e CARVALHO, 2010). 
Parceiro econômico brasileiro e de relações históricas e diplomáticas, Portugal, como país membro da União Europeia, estabeleceu em 2005 a adoção das normas internacionais de contabilidade através do Regulamento (CE) n. ${ }^{\circ}$ 1606/2002. Elaborado pelo Parlamento Europeu, tal regulamento apresenta como objetivo:

a utilização das normas internacionais de contabilidade na Comunidade Europeia, com vista a harmonizar as informações financeiras apresentadas pelas sociedades, por forma a assegurar um elevado grau de transparência e de comparabilidade das demonstrações financeiras e, deste modo, um funcionamento eficiente do mercado de capitais da Comunidade e do mercado interno.

Para Guimarães (2011), a convergência contabilística tem ocupado um papel fundamental na consolidação e desenvolvimento da contabilidade, não só por efeito da sua função harmonizadora, o que tem permitido um conhecimento mais aprofundado e consolidado do pensamento contabilístico, mas também, e principalmente porque tem constituído um fator importante para a criação de hábitos e iniciativas de investigação nesta importante área do conhecimento.

\subsection{Caracterização do problema}

Após a convergência do Brasil e de Portugal às normas internacionais, torna-se necessário analisar os efeitos causados por essas mudanças. Para alguns autores como Tua Pereda (1996), Carlson (1997) e Beuren e Brandão (2002), os vínculos como as relações comerciais e a proximidade linguística beneficiam o estudo acerca da harmonização. Diante do exposto, surge a seguinte problemática: Quais as percepções dos discentes do curso de ciências contábeis no Brasil e em Portugal acerca do processo de convergência aos Padrões Internacionais de Contabilidade?

\section{REFERENCIAL TEÓRICO}

\subsection{A diversidade e a harmonização contabilística}

Para Pereira, Estevam e Almeida (2009, p.22), a necessidade de harmonização contabilística surge da constatação de que as práticas contábeis variam de país para país, ou seja, da existência de diferentes sistemas contabilísticos. Tal diversidade de sistemas remota de fatores específicos que tiveram influência no desenvolvimento da contabilidade em cada nação.

A relevância do sistema legal (Roman law e o Common law) como fator determinante nessas diferenças contabilísticas é compartilhada por autores como Choi e Muller,1992; Radebaugh e Gray, 1997. Países cuja estrutura legal assenta no direito Romano (Roman law) possuem uma orientação legalista onde as leis das sociedades e os códigos comerciais estabelecem regras detalhadas para a contabilidade e para o relato financeiro. Em uma vertente distinta, os países com estrutura legal baseada no direito comum (Common law) apresentam normas estabelecidas pelos organismos profissionais independentes, que apesar de não serem dotadas de força de lei, são aceites e reconhecidas pelos profissionais de contabilidade (DOUPNIK E SALTER, 1995).

O modo como a fiscalidade relaciona-se com a contabilidade, também contribui para a diversidade a nível internacional (RODRIGUES, 2005). Nos países de influência europeia continental, tem-se uma marcante predominância de impostos na contabilidade e desse modo, é perceptível a elaboração das informações financeiras com base nas exigências específicas 
do Fisco. Por outro lado, nos países de raiz anglo-saxônica, as demonstrações contábeis apresentam como principal objetivo fornecer uma imagem verdadeira e apropriada da posição financeira da entidade, de modo a não possibilitar interferências dos critérios fiscais (PEREIRA, ESTEVAM, ALMEIDA; 2009).

Outros autores como Rivera (1989); Meek e Saudagaran (1990) e Zarzeski (1996) enfatizam o grau de sofisticação do mercado de capitais em um país, os níveis de inflação e outras variáveis socioeconômicas e culturais como causas da diversidade contabilística.

Tais diversidades nas doutrinas contábeis de cada país representam um obstáculo à otimização dos recursos econômicos numa economia cada vez mais global, na medida em que implicam maiores custos para as empresas multinacionais na preparação de sua informação financeira e, concomitantemente, dificulta a compreensão dessas demonstrações aos usuários não familiarizados com normas de outros países. (RODRIGUES, GUERREIRO; 2004)

Desse modo, a partir da década de 70 , nomeadamente com a criação de organismos supranacionais orientados para a comparabilidade da contabilidade ao nível internacional, emerge a busca por uma contabilidade de "linguagem universal", ou seja, uma contabilidade com normas internacionalmente aceitas.

\subsection{A convergência às Normas Internacionais de Contabilidade em Portugal}

De acordo com Jarne (1997), a evolução do sistema contabilístico português ao longo das últimas décadas foram acentuadas, tendo decorrido em consequência da aproximação do normativo português, principalmente através das diretrizes contabilísticas emitidas pela a Comissão de Normalização Contabilística (CNC), ao normativo do International Accounting Standards Board (IASB).

Órgão português tecnicamente independente, a Comissão de Normalização Contabilística foi criada em 1977, através do decreto-lei no 44/77 e apresenta atualmente por missão:

a emissão de normas e o estabelecimento de procedimentos contabilísticos, harmonizados com as normas comunitárias europeias e internacionais da mesma natureza, tendo em vista a melhoria da qualidade da informação financeira das entidades que sejam obrigadas a aplicar o Sistema de Normalização Contabilística (SNC), bem como promover as ações necessárias para que tais normas sejam efetivas e adequadamente aplicadas pelas entidades a elas sujeitas.

Os esforços efetuados pelo CNC para a harmonização contábil portuguesa às normas internacionais de contabilidade tiveram inicio em 1986, com a entrada do país na União Europeia. Como país membro, houve a necessidade de adaptação da legislação nacional à legislação comunitária, através das Diretivas $n^{\circ}$ 78/660/CE e $n^{\circ}$ 83/349/CEE. Tais transposições, entre outras, fizeram com que a convergência contabilística ocupasse um lugar central nas políticas contábeis do país (Pereira et al 2009,p.94).

Contudo, foi apenas na década de noventa que a CNC iniciou a emissão de algumas diretrizes contábeis estreitamente ligadas às do IASB. Ferreira (1998:806) observa esse período como a repercussão, nas diretrizes contabilísticas portuguesas, de normas com caráter internacional em detrimento da influência francesa, até então base para o normativo nacional. Essa aproximação com as normas do IASB está evidente na DC n. ${ }^{\circ}$ 18/97 - Objetivo das Demonstrações Financeiras e Princípios Contabilísticos Geralmente Aceites: 
A CNC, ao privilegiar uma perspectiva conceitual de substância econômica para o relato financeiro, considera que o uso de Princípios Contabilísticos Geralmente Aceitos deve-se subordinar à seguinte hierarquia:

i) os constantes do Plano Oficial de Contabilidade;

ii) os constantes da Diretrizes Contabilísticas;

iii) os divulgados nas normas internacionais de contabilidade do IASB.

Nota-se, todavia, que as normas internacionais de contabilidade ainda não estavam prioritariamente integradas ao normativo nacional. Morais e Lourenço (2005) demonstra esse fato ao dividir o processo de convergência português em duas fases: uma primeira onde algumas normas do IASB são traduzidas e adotadas pelo normativo de Portugal e, numa segunda fase, onde é observada a aplicação direta das IAS pelas empresas ou pelo ajustamento do normativo nacional às diretivas comunitárias revistas.

Essa segunda fase segue a estratégia do Parlamento Europeu relativa à adoção das Normas Internacionais de Contabilidade em toda a comunidade europeia e com o objetivo de assegurar um elevado grau de transparência e de comparabilidade das demonstrações financeiras a um nível internacional. Dessa forma, o Decreto-Lei $n^{\circ} 35 / 2005$ cria um quadro jurídico nacional integrado ao regime contabilístico previsto no Regulamento (CE) $\mathrm{n}^{\mathbf{o}}$ $1606 / 2002$, conforme disposto no artigo $11^{\circ}$ :

As entidades cujos valores mobiliários estejam admitidos à negociação num mercado regulamentado devem, nos termos do artigo $4^{\circ}$ do Regulamento (CE) n. ${ }^{\circ}$ 1606/2002, do Parlamento Europeu e do Conselho, de 19 de Julho, elaborar as suas contas consolidadas em conformidade com as Normas Internacionais de Contabilidade adotadas nos termos do artigo $3 .^{\circ} \mathrm{do}$ Regulamento (CE) n. ${ }^{\circ} 1606 / 2002$, do Parlamento Europeu e do Conselho, de 19 de Julho, a partir do exercício que se inicie em 2005.

Apesar dessa convergência às IFRS/IAS, o referido Decreto-lei estipula que para efeitos fiscais, as entidades portuguesas são obrigadas a manter a sua contabilidade organizada de acordo com a normalização contabilística nacional. Tal fato, dentre outros, para Rodrigues (2005), não contribuíram para o desenvolvimento da contabilidade em Portugal, nomeadamente devido ao aumento dos custos de elaboração das demonstrações, além da dificuldade ao se avaliar o desempenho econômico e financeiro das entidades quando se tem dois sistemas de medição distintos.

Neste cenário, os esforços da CNC centraram-se na modernização e evolução da regulamentação contabilística portuguesa. A comissão iniciou então um conjunto de trabalhos visando à apresentação de um novo modelo de normalização contabilística nacional, o Sistema de Normalização Contabilística (SNC) cuja aprovação e publicação são culminadas pelo Decreto-Lei n. ${ }^{\circ} 158 / 2009$, de 13 de Junho.

De acordo com a CNC, o Sistema de Normalização contabilística, que entrou em vigor em 2010, prefigura um modelo baseado em princípios e não em regras, aderente ao modelo IASB adoptado na União Europeia, mas garantindo a compatibilidade com as Diretivas Contabilísticas Comunitárias. É, portanto, um modelo que se adapta às normas internacionais de contabilidade e concomitantemente, sem distorcer a homogeneidade, qualidade e coerência globais, elimina tratamentos pouco ou nada aplicáveis à realidade portuguesa.

\subsection{A convergência às Normas Internacionais de Contabilidade no Brasil}


No Brasil, o marco inicial da harmonização contábil se deu através da promulgação da Lei $n^{\circ}$ $11.638 / 07$, a qual foi promulgada em 28 de dezembro de 2007, entrando em vigor no primeiro dia de janeiro do ano de 2008. Tal lei altera e introduz novos dispositivos à lei $n^{\circ}$ 6.404/76, a qual é relativa às sociedades por ações, objetivando alterações de procedimentos contábeis.

De acordo com o Memorando de Entendimentos entre o CFC, CPC e o IASB, o Comitê de Pronunciamentos contábeis foi criado pela Resolução CFC nº $1.055 / 05$ idealizado a partir da união de esforços de diversas entidades como a Associação Brasileira das Companhias Abertas (ABRASCA), Associação dos Analistas e Profissionais de Investimento do Mercado de Capitais (APIMEC NACIONAL), BM\&FBOVESPA S.A - Bolsa de Valores, Mercadorias e Futuros, Conselho Federal de Contabilidade (CFC), Fundação Instituto de Pesquisas Contábeis, Atuariais e Financeiras (FIPECAFI) e Instituto dos Auditores Independentes do Brasil (IBRACON). O CPC foi criado a partir da necessidade de convergência internacional das normas contábeis, da centralização na emissão de normas dessa natureza e da representação e processo democráticos na produção dessas informações.

O Comitê de Pronunciamentos Contábeis tem como objetivo, segundo a resolução $n^{\circ}$ 1.055/05:

o estudo, o preparo e a emissão de Pronunciamentos Técnicos sobre procedimentos de Contabilidade e a divulgação de informações dessa natureza, para permitir a emissão de normas pela entidade reguladora brasileira, visando à centralização e uniformização do seu processo de produção, levando sempre em conta a convergência da Contabilidade Brasileira aos padrões internacionais.

Assim, o CPC tem o papel mais importante no que tange ao processo de harmonização contábil no Brasil, emitindo normas norteadoras aos usuários da contabilidade para que seja possível a total integração entre os países no que se refere aos procedimentos e fatos contábeis. Porém, a adoção destas normas é feita sempre buscando a adaptação das normas internacionais às brasileiras, preocupando-se com a sua contextualização ao país que está em fase de implementação. Portanto, o processo modificativo que vem sofrendo a contabilidade no Brasil tem de estar acompanhado da participação efetiva de profissionais da área (contabilistas, docentes, discentes, auditores, etc.), para que a adaptação às normais internacionais possa ocorrer de forma coerente, reduzindo a quantidade de termos intraduzíveis ou não aplicáveis ao país, podendo criar conflitos e dificuldades na discussão deste processo.

\subsection{A importância do discente e do ensino no processo de harmonização}

As alterações ocorrentes no âmbito contábil são reflexos de fatos que acontecem no contexto global referente à cultura, comportamento, tecnologia e outros aspectos. Portanto, devido às novas exigências atuais das entidades, decorrentes das mudanças globais, o contador precisa se mostrar capaz de ir além de apenas dominar os processos de escrituração e divulgação de demonstrações contábeis. Para tanto, é necessário que o contador possua conhecimento crítico para pensar a organização por meio dos conhecimentos contábeis, sendo capaz de articular competências de sua área de atuação às necessidades do contexto organizacional atual (LAFFIN, 2002). 
Ainda segundo Laffin (2002), as informações originárias dos procedimentos contábeis não podem ser somente transcrições e leituras dos fenômenos passados e devidamente registrados pela contabilidade, mas atualmente, as organizações demandam por informações confiáveis, e que por meio destas possam tomar decisões em favor dos objetivos e metas definidos por elas.

Assim, é possível perceber que as mudanças que vêm ocorrendo na ciência contábil envolvem todas as partes integrantes desta, tendo docentes e discentes um papel de suma importância no que tange à realização de uma adaptação a estas modificações de maneira coerente.

Segundo Laffin (2002, p.162), para que seja possível estruturar a organização do trabalho do professor de contabilidade, torna-se necessário:

1. Observar que a diversidade na sua formação profissional exige também uma diversidade de leitura de mundo e de formas de atuação segundo os limites e possibilidades encontrados nas diversas instituições de ensino superior;

2. Refletir sobre a formação do professor no âmbito dos conhecimentos contábeis específicos;

3. Analisar e dominar opções teórico-metodológicas que sejam capazes de responder à sua concepção de trabalho pedagógico e sua interferência no real;

4. Configurar possibilidades de formação continuada para o professor de contabilidade do ensino superior.

Portanto, faz-se indispensável uma constante atualização e domínio de conhecimentos da parte do docente, desta forma, garantindo ao estudante estímulo de aprendizado. É sabido que tão somente ao professor não cabe a responsabilidade do incentivo ao aluno, mas também a estrutura física do ambiente de ensino e também fatores externos ao contexto físico da instituição de ensino, como o ambiente familiar e situação financeira. Porém, fica evidente quão importante é a influência que exibe o docente, com relação ao conhecimento científico, ante o aluno.

Esta relação de troca de conhecimentos e processo de aprendizagem entre docentes e alunos é confirmada quando Freire (1996, p.77) afirma que "toda prática educativa demanda a existência de sujeitos, um, que ensinando, aprende, outro, que aprendendo ensina". A transmissão de conhecimentos é feita de sujeito à sujeito, onde aquele que aprende está pronto à ensinar, compartilhar conhecimento. Assim pode se observar na contabilidade, onde os conhecimentos relativos às conquistas alcançadas pelas mudanças ocorridas são disseminados e pouco a pouco presentes de modo arraigado, fatos estes oriundos de uma qualidade de ensino adequada.

Cabe ao discente, portanto, o aprendizado efetivo da ciência contábil ao ponto de estar apto à transmissão de conhecimento, a fim de que, em longo prazo, o maior beneficiário deste fato seja o crescimento da ciência contábil e todos que nela se incluem, valorizando esta ciência e seus ramos, tornando-a robusta e com profissionais capacitados, atualizados e preparados para novas mudanças a ocorrerem no futuro.

\section{METODOLOGIA}

\subsection{Características da Pesquisa}


Esta pesquisa buscou realizar um estudo comparativo a respeito da percepção dos discentes do curso de Ciências Contábeis do Brasil e Portugal, através de questionários aplicados aos alunos de forma presencial.

Os questionários foram aplicados entre o final do ano de 2011 e primeiro semestre do ano de 2012 em três Instituições de Ensino brasileiras, as quais eram públicas e privadas, especificamente na Região Metropolitana do Recife, e uma Universidade portuguesa. A amostra foi composta por 159 respondentes, dentre os quais 112 foram os discentes de instituições brasileiras e 47 respondentes compondo a amostra dos discentes em Portugal.

O questionário foi dividido em dois blocos, o primeiro sobre dados de perfil dos discentes, evidenciando características como gênero, idade e dedicação exclusiva aos estudos. $O$ segundo bloco foi composto por questões dispostas em uma Escala Likert de 5 pontos concernentes à percepção dos mesmo sobre a convergência da contabilidade aos padrões internacionais.

Os dados encontrados foram tabulados no Microsof Excel e posteriormente fez-se uso do programa Statistical Package for Social Sciences (SPSS) para execução de análise descritiva dos dados obtidos, a fim de evidenciar características genéricas da amostra.

\section{ANÁLISE DOS DADOS}

\subsection{Análise descritiva dos dados}

\subsubsection{Perfil dos Respondentes}

A primeira pergunta feita aos entrevistados diz respeito ao curso que os mesmos estão matriculados, na qual se constatou que $97 \%$ dos respondentes brasileiros e $74 \%$ dos portugueses são estudantes do curso de Ciências Contábeis. Os outros 3\% dos brasileiros e $26 \%$ dos portugueses afirmaram estar estudando outas áreas de formação.

No que se refere à dedicação dos respondentes aos estudos, 9,8\% dos brasileiros se dedicam exclusivamente aos estudos e $61,7 \%$ dos portugueses afirmaram apenas estudar. Tal diferença entre os dois países pode ser devido ao fato de muitos estudantes, que se encontram na Universidade de Aveiro em Portugal, serem de outros países e estão neste país apenas estudar, enquanto que os estudantes brasileiros pesquisados, em sua maioria, possuem residência fixa aqui no Brasil e por isso conseguem realizar outras atividades além dos estudos.

Tabela 1 - Formação dos Respondentes e Dedicação aos Estudos

\begin{tabular}{l|r|r|r|r|r|r}
\hline & \multicolumn{2}{|c|}{ Formação } & Total & \multicolumn{2}{c}{$\begin{array}{c}\text { Dedicação } \\
\text { Exclusiva }\end{array}$} & Total \\
\hline & $\begin{array}{c}\text { Ciências } \\
\text { Contábeis }\end{array}$ & Outros & & Não & \multicolumn{1}{c}{ Sim } & \\
\hline Brasil & 109 & 3 & 112 & 97 & 11 & 112 \\
\hline Portugal & 35 & 12 & 47 & 18 & 29 & 47 \\
\hline Total & 144 & 15 & 159 & 28 & 32 & 159 \\
\hline
\end{tabular}

Fonte: Dados da Pesquisa, 2012

Com relação ao gênero dos respondentes, a maioria da amostra portuguesa é representada pelas mulheres. Assim, 48,2\% dos estudantes brasileiros e 55,3\% dos portugueses afirmaram ser do gênero feminino e quase $3 \%$ dos brasileiros preferiram não responder a esta questão. 
Desta forma, percebe-se que há uma pequena diferença no perfil dos estudantes dos dois países analisados.

No tocante a idade dos respondentes, ambos os países apresentaram uma concentração de respostas na faixa etária entre 20 e 25 anos, sendo que $67 \%$ brasileiros e $76,6 \%$ portugueses assinalaram tal alternativa. Nenhum estudante de Portugal afirmou ter mais de 25 anos e $11,6 \%$ dos brasileiros afirmaram estar nesta faixa etária. Observou-se também que $12,5 \%$ dos brasileiros e 4,2\% dos portugueses afirmaram possuir entre 18 e 20 anos de idades, e que dez respondentes brasileiros e nove estudantes de Portugal optaram por não responder tal alternativa.

Tabela 2 - Gênero e Idade dos Respondentes

\begin{tabular}{l|r|r|r|r|r|r|r|r|r}
\hline & \multicolumn{3}{|c|}{ Gênero } & Total & \multicolumn{3}{c|}{ Faixa Etária } & Total \\
\hline & & & & & $18-20$ & $20-25$ & $\begin{array}{l}\text { Mais } \\
\text { de 25 }\end{array}$ & Missing & \\
\hline Brasil & 55 & 54 & 3 & 112 & 14 & 75 & 13 & 10 & 112 \\
\hline Portugal & 21 & 26 & 0 & 47 & 2 & 36 & 0 & 9 & 47 \\
\hline Total & 76 & 80 & 3 & 159 & 16 & 111 & 13 & 19 & 159 \\
\hline
\end{tabular}

Fonte: Dados da Pesquisa, 2012

A última pergunta sobre os dados demográficos dos respondentes foi com relação às disciplinas que os mesmos estão estudando. Desta forma, estabeleceram-se sete grupos de disciplinas:

1) Grupo 1- Teoria da Contabilidade, Contabilidade Internacional e Tópicos contemporâneos de contabilidade;

2) Grupo 2 - Contabilidade Básica (geral ou comercial), Intermediária e Avançada;

3) Grupo 3 - Auditoria e Perícia Contábil;

4) Grupo 4 - Gerencial, Custos e Controladoria;

5) Grupo 5 - Análise das Demonstrações Contábeis;

6) Grupo 6 - Finanças;

7) Grupo 7 - Outros.

Assim, os dados tabulados demonstram que o grupo de maior representatividade é o de número dois, num total de 82 respondentes, seguido do grupo três com 74 das respostas distribuídos entre brasileiros e estudantes de Portugal.

Pela convergência já ter sido implantada em ambos os países, o grupo 1, representado pelas disciplinas relacionadas a contabilidade internacional, foi o de menor representação, com apenas 7 respondentes.

Tabela 3 - Disciplinas que estão sendo cursadas pelos Respondentes

\begin{tabular}{l|r|r|r|r|r|r|r|r}
\hline & \multicolumn{7}{|c}{ Grupos de Disciplinas } \\
& Grupo 1 & Grupo 2 & Grupo 3 & Grupo 4 & Grupo 5 & Grupo 6 & Grupo 7 & Total $^{*}$ \\
\hline Brasil & 5 & 65 & 62 & 49 & 32 & 32 & 21 & 266 \\
\hline Portugal & 2 & 17 & 12 & 10 & 24 & 10 & 19 & 94 \\
\hline Total $^{*}$ & 7 & 82 & 74 & 59 & 56 & 42 & 40 & 360 \\
\hline
\end{tabular}


Fonte: Dados da Pesquisa, 2012. ${ }^{1}$

\subsubsection{Percepção dos Estudantes sobre o Processo de Convergência da Contabilidade aos Padrões Internacionais}

Neste grupo objetivou-se avaliar o grau de concordância ou discordância dos respondentes em relação ao processo de convergência. A primeira afirmação foi: "o processo de convergência das normas brasileiras às normas internacionais de contabilidade é bem vindo, pois traz mais benefícios do que custos às empresas". As respostas mostraram que $2,7 \%$ dos estudantes brasileiros e $14,8 \%$ dos estudantes portugueses posicionaram-se indiferentes diante da assertiva.

Neste contexto, $92 \%$ dos brasileiros e $72,4 \%$ dos portugueses afirmaram concordar que o processo de convergência das normas brasileiras de contabilidade às normas internacionais é bem vindo, pois traz mais benefícios do que custos às empresas.

A segunda perquirição buscou verificar se "a adoção das normas internacionais de contabilidade do IASB facilitará a inserção de empresas brasileiras no mercado internacional em função da redução dos custos de elaboração das Demonstrações Contábeis". Neste sentido, 76,8\% dos brasileiros e 95,7\% dos portugueses concordaram com a afirmativa, nenhum estudante de Portugal discordou desta assertiva e 9 (nove) estudantes, distribuídos entre Brasil e Portugal, mostraram-se indiferentes a esta questão.

Tabela 4 - Aceitação do Processo pelos Estudantes e Opinião sobre Inserção das Empresas

\begin{tabular}{|c|c|c|c|c|c|c|c|c|c|c|}
\hline & & \multicolumn{3}{|c|}{ Aceitação do Processo } & \multirow{2}{*}{ Total } & \multicolumn{3}{|c|}{ Inserção das Empresas } & \multirow{2}{*}{ Total ${ }^{*}$} \\
\hline & & & Discordo & Indif. & Concordo & & Discordo & Indif. & Concordo & \\
\hline \multirow{5}{*}{ País } & \multirow[b]{2}{*}{ Brasil } & Count & 6 & 3 & 103 & 112 & 17 & 7 & 86 & 110 \\
\hline & & $\begin{array}{c}\text { \% within } \\
\text { País }\end{array}$ & $5,3 \%$ & $2,7 \%$ & $92 \%$ & $100,0 \%$ & $15,1 \%$ & $6,3 \%$ & $76,8 \%$ & $98,2 \%$ \\
\hline & & & & & & & 2 & & & \\
\hline & \multirow[b]{2}{*}{ Portugal } & Count & 6 & 7 & 34 & 47 & 0 & 2 & 45 & 26 \\
\hline & & $\begin{array}{l}\text { \% within } \\
\text { País }\end{array}$ & $12,8 \%$ & $14,8 \%$ & $72,4 \%$ & $100,0 \%$ & $0,0 \%$ & $4,3 \%$ & $95,7 \%$ & $100,0 \%$ \\
\hline \multicolumn{2}{|c|}{ Total } & Count & 12 & 10 & 137 & 159 & 17 & 9 & 131 & 157 \\
\hline
\end{tabular}

Fonte: Dados da Pesquisa, 2012²

Ainda no tocante à convergência, uma das questões buscou avaliar se "os profissionais de contabilidade no Brasil estão despreparados para implementação das normas internacionais de contabilidade". O objetivo, neste caso, foi verificar se os estudantes percebem que os contabilistas estão, ou não, preparados para implementar a contabilidade nos padrões internacionais. Constatou-se que a maioria dos estudantes, de ambos os países, concordam com a afirmativa, mostrando assim que entendem que os contadores não estão prontos e isso pode afetar a qualidade das informações contábeis, esta maioria foi tida em $84,9 \%$ dos estudantes brasileiros e 57,4\% dos portugueses. Apenas três brasileiros $(2,7 \%)$ mostraram-se

\footnotetext{
${ }^{1}$ Neste item, os entrevistados responderam mais de uma alternativa. Isto porque, tais estudantes estão cursando mais de uma disciplina no período em análise. Portanto, a soma do total apresentou mais respostas, tendo em vista que um único entrevistado afirmou estar cursando disciplinas que pertencem a grupos diversos.
} 
indiferente a esta assertiva, diferentemente dos portugueses os quais demonstraram ser indiferente em $23,4 \%$.

Perquiriu-se também aos respondentes o que os mesmos achavam das Instituições Educacionais. Neste sentido, afirmou-se: "As instituições educacionais do seu país estão adaptadas às mudanças decorrentes da adoção das normas do IASB". Assim, pôde-se constatar que a maioria dos portugueses (68\%) afirmou ter confiança no ensino de suas instituições e no Brasil os estudantes mostraram-se praticamente equilibrados entre discordar de tal assertiva e concordar com a mesma. Tal fato pode ser explicado, talvez, pela convergência da contabilidade aos padrões internacionais ter ocorrido primeiro em Portugal do que no Brasil.

Tabela 5 - Qualificação dos Profissionais e das Instituições Educacionais

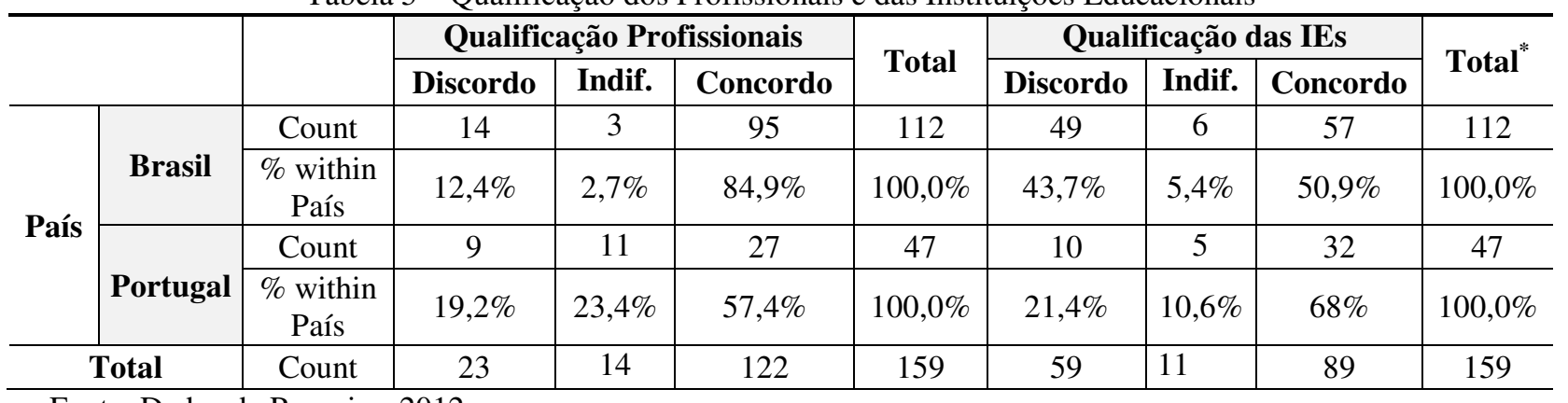

Fonte: Dados da Pesquisa, 2012

Dando seguimento à análise dos dados, a afirmativa que se segue analisa o seguinte: "Como estudante do curso de Ciências Contábeis me sinto obrigado a estudar as mudanças ocorridas com a adoção das normas contábeis internacionais". Sendo assim, 99,1\% dos estudantes brasileiros e $89,3 \%$ dos estudantes de Portugal afirmaram que se sentem na obrigação de estudar as mudanças impostas pela convergência tendo em vista que vai impactar nas suas formações como novos profissionais de contabilidade.

Além disso, buscou-se investigar se "A adoção das normas internacionais de contabilidade foi bem discutida por toda a classe contábil". Percebeu-se que a minoria dos brasileiros e portugueses $(36,7 \%$ e $19,1 \%$, respectivamente) discorda da questão, demonstrando que acreditam que o processo não foi bem discutido pela classe contábil como um todo. Pôde-se constatar ainda que um percentual significativo de portugueses $(38,3 \%)$ mostrou-se indiferentes a esta alternativa. Portanto, a maioria dos estudantes do Brasil $(55,3 \%)$ e uma grande parte dos estudantes de Portugal $(42,7 \%)$ afirmaram que concordam com a assertiva, ou seja, acreditam que o processo foi bem discutido.

Tabela 6 - Estudar as Mudanças e Discussão do Processo

\begin{tabular}{|c|c|c|c|c|c|c|c|c|c|c|}
\hline & & & \multicolumn{3}{|c|}{ Estudar as Mudanças } & \multirow{2}{*}{ Total } & \multicolumn{3}{|c|}{ Discussão do Processo } & \multirow{2}{*}{ Total $^{*}$} \\
\hline & & & Discordo & Indif. & Concordo & & Discordo & Indif. & Concordo & \\
\hline \multirow{4}{*}{ País } & \multirow[b]{2}{*}{ Brasil } & Count & 0 & 1 & 111 & 112 & 41 & 9 & 62 & 112 \\
\hline & & $\begin{array}{c}\% \text { within } \\
\text { País }\end{array}$ & $0,0 \%$ & $0,9 \%$ & $99,1 \%$ & $100,0 \%$ & $36,7 \%$ & $8 \%$ & $55,3 \%$ & $100,0 \%$ \\
\hline & \multirow[b]{2}{*}{ Portugal } & Count & 2 & 3 & 42 & 47 & 9 & 18 & 20 & 47 \\
\hline & & $\begin{array}{c}\text { \% within } \\
\text { País }\end{array}$ & $4,3 \%$ & $6,4 \%$ & $89,3 \%$ & $100,0 \%$ & $19,1 \%$ & $38,3 \%$ & $42,7 \%$ & $100,0 \%$ \\
\hline \multicolumn{2}{|c|}{ Total } & Count & 2 & 4 & 153 & 159 & 50 & 27 & 82 & 159 \\
\hline
\end{tabular}

Fonte: Dados da Pesquisa, 2012 
A última pergunta feita aos docentes diz respeito às suas opiniões sobre a importância do processo de convergência aos padrões internacionais. Neste contexto, constatou-se que 69,6\% dos respondentes brasileiros e $83 \%$ dos estudantes de Portugal afirmaram acreditar que o processo de convergência é muito importante para a contabilidade. Nenhum respondente do Brasil afirmou não acreditar na importância da convergência e apenas um estudante de Portugal respondeu não acreditar. Por fim, 14 respondentes, dentre os dois países, mostraramse indiferente a esta assertiva.

\section{CONCLUSÃO}

Esta pesquisa teve como principal objetivo verificar as percepções dos discentes de universidades no Brasil e em Portugal perante o processo de convergência da contabilidade aos padrões internacionais.

Neste sentido, verificou-se que $92 \%$ dos brasileiros e $72,4 \%$ dos portugueses afirmaram concordar que o processo de convergência das normas brasileiras de contabilidade às normas internacionais é bem vindo, pois traz mais benefícios do que custos às empresas. Além disso, constatou-se que $76,8 \%$ dos estudantes brasileiros e $95,7 \%$ dos estudantes portugueses asseguraram que a adoção das normas internacionais de contabilidade do IASB facilitará a inserção de empresas brasileiras no mercado internacional, em função da redução dos custos de elaboração das Demonstrações Contábeis.

Os resultados revelaram também que $84,9 \%$ dos discentes do Brasil e 57,4\% dos discentes de Portugal afirmaram que não acreditam na capacitação dos profissionais de contabilidade para as mudanças decorrentes da adoção das normas do IASB, demonstrando que os mesmos percebem que os contabilistas estão despreparados para colocar em prática as mudanças.

Por fim, buscou-se conhecer a percepção dos respondentes sobre o grau de importância atribuído à convergência e o estudo concluiu que a maioria dos discentes, sendo 69,6\% dos respondentes brasileiros e $83 \%$ dos estudantes de Portugal, afirmou acreditar que o processo de convergência é muito importante para a contabilidade.

Esta pesquisa tem como limitação o uso de amostra intencional não representativa da população. Os autores desta pesquisa pretendem expandir a amostra para outros países e para outros grupos que são impactados pela convergência, a exemplo dos docentes e contabilistas.

\section{REFERÊNCIAS}

BEUREN, I. M.; BRANDÃO, J. F., "Demonstrações contábeis no Mercosul: estrutura, análise e harmonização" En: Brasil 2002. ed: ATLAS

CARLSON, P. "Advancing The Harmonization of International Accounting Standards: Exploring an Alternative Path", The International Journal of Accounting,Vol.32, N.3. 1997.

CARVALHO, N.; LEMES, S. Contabilidade Internacional para Graduação, Ed. Atlas, 2010 .

Memorando de Entendimentos entre a Junta de Normas Internacionais de Contabilidade (IASB), o Conselho Federal de Contabilidade (CFC) e o Comitê de Pronunciamentos Contábeis (CPC). 2010. Disponível em: $<$ http://www.ifrs.org/NR/rdonlyres/B7F3624B-1DFF-4E96-BFF04BF74D1C650B/0/MoUBrazil.pdf>. Acesso em: 21/05/2012. 
CHOI, Frederick D. S.; MUELLER, Gerhard G. International Accounting. 2. ed. New Jersey: Prentice-Hall, 1992.

CONSELHO FEDERAL DE CONTABILIDADE. Resolução n 1.055, de 7 de outubro de 2005. Disponível em: <http://www.cfc.org.br/sisweb/sre/detalhes_sre.aspx?Codigo=2005/001055>. Acesso em 23 de maio de 2012.

Doupnik, T.S. \& Salter, S.B. External environment, Culture and Accounting Practice: A Preliminary Test of A General Model of International Accounting Development. International Journal of Accounting, pp. 189-207, 1995.

EVANS, T. G., TAYLOR, M. E. \& HOLZMANN, O. International accounting \& ryeporting. 2ed. USA : IPT Company, 1994.

FREIRE, P. Pedagogia da autonomia: saberes necessários à prática educativa. 20 ed. São Paulo: Paz e Terra, 1996.

GUIMARÃES, J. F. C. Estudo sobre a Normalização Contabilística em Portugal, ed. Vida Economica, 2011.

IUDÍCIBUS, S. de; MARION, J. C. Introdução à teoria da contabilidade: Para nível de graduação. 3.ed. São Paulo: Atlas, 2002.

IJIRI, Y. Theory of ACcounting Measurement, NY; American Association of Accountants, 1975.

JARNE, J. I. J. Clasificación y evolución internacional de los sistemas contables. Madrid, AECA Asociación Española de Contabilidad y Administración de Empresas, 1997.

LAFFIN, M. De Contador a Professor: A trajetória da docência no ensino superior de contabilidade. 2002. Tese de Doutorado. Programa de Pós- Graduação em Engenharia de Produção da Universidade Federal de Santa Catarina.

MENDONÇA NETO, O. R.; CARDOSO, R. L.; RICCIO, E. L.; SAKATA, M. C. G. Estudo sobre as Publicações Científicas em Contabilidade: uma Análise de 1990 até 2003. In : ENANPAD,28.2004, Curitiba. Anais... Rio de Janeiro: ANPAD, 2004.

MEEK, G. K., SAUDAGARAN, S. M., A Survey of Research on Financial Reporting in a Transnational Context, Journal of Accounting Literature, Vol. (9), 145-182, 1990.

MORAIS, Isabel; LOURENÇO, Isabel Costa. Aplicação das Normas do IASB em Portugal, Publisher Team, Lisboa, 2005.

PEREIRA, R.; ESTEVAM, M.; ALMEIDA, R. Harmonização Contabilística Internacional - Análise das suas Implicações em Portugal, $1^{\text {a }}$ Ed., Lisboa, Deplano Network AS, 2009.

RADEBAUGH. L. H. e GRAY, S. J. International Accounting Multinational Enterprises. 4.ed USA : John Wiley \& Sons, Inc, 1997.

RIVERA, J. M. The internationalization of accounting standards: Past problems and current prospects, The International Journal of Accounting, 24(4), 320-341, 1989.

RODRIGUES, J. Adopção em Portugal das Normas Internacionais de Relato Financeiro, Áreas, Lisboa, 2005.

RODRIGUES, L. L. e Guerreiro, M. A. A Convergência de Portugal com as Normas Internacionais de Contabilidade. Lisboa: Publisher Team, 2004. 
TUA PEREDA. J. Ampliar el Marco Conceptual de la Información Financeira, Boletín AECA,n.40, Fevereiro-Junho de 1996.

WEFFORT, E. F. J. Brasil e a Harmonização Contábil Internacional. 1ed. Atlas, 2005.

ZARZESKI, M.T. Spontaneous harmonization effects of culture and market forces on accounting disclosure practices. Accounting Horizons. Vol. 10: 18-37, 1996. 